\title{
"Que enloquezcan mis personajes, no yo": Instancias de autoficción en la obra de Andrés Caicedo.
}

\section{Resumen}

En la escritura del colombiano Andrés Caicedo (1951 - 1977), es evidente la intención del autor en (des)articularse y desdoblarse como figura protagónica en sus (no)ficciones. Proponemos una doble lectura autoficcional de dos libros póstumos, Mi cuerpo es una celda (2008) y Calicalabozo (2008), que analice la ficcionalización de su vida en su "autobiografía" y las implicaciones autorreferenciales de su colección de cuentos. Caicedo reconstruye su laberíntica Cali natal como una extensión letrada de sí mismo, plasmando una (o varias) identidad(es) esquizofrénica(s). Su escritura misma queda poblada de espejos hostiles proyectados a través de una focalización cinematográfico que documenta y ficcionaliza su entorno personal en una ciudad latinoamericana gótica y enajenante. Se considerará una multiplicidad de definiciones y modalidades de la autoficción como herramienta autoral y como género literario para demostrar cómo Caicedo elabora una leyenda de sí mismo paralela y nutrida de su escritura, un doble discurso tan insidioso e inseparable que supera hasta "la muerte del autor".

Palabras claves

Andrés Caicedo; Alberto Fuguet; Autoficción; Autobiografía; Cali (Colombia); Teoría de cine; Muerte del autor.

\begin{abstract}
In the œuvre of Colombian Andrés Caicedo (1951 - 1977), there is an evident intent of the author in (dis)articulating himself as the protagonist of his (non)fictions. We propose an autofictional double reading of two posthumous texts, Mi cuerpo es una celda (2008) and Calicalabozo (2008), which analyzes the fictionalization of his life in his "autobiography" and the auto referential implications of his short story collection. Caicedo reconfigures his native labyrinthine Cali as a lettered extension of himself, shaping one (or various) schizophrenic identity(ies). His very writing becomes inhabited by hostile mirror images of himself projected through a cinematographic focalization that documents and fictionalizes his
\end{abstract}


surroundings in a gothic and alienating Latin American cityscape. We will consider various definitions and modalities of autofiction not only as an authorial tool but also as a literary genre in order to demonstrate how Caicedo weaves an urban myth of himself parallel to and nurtured by his writing, a double discourse so inseparable and insidious that it manages to overcome the "Death of the Author".

Keywords Andrés Caicedo; Alberto Fuguet; Autofiction; Autobiography; Cali (Colombia); Film Theory; Death of the Author.

\author{
"Toda autobiografía es ficcional \\ y toda ficción autobiográfica." \\ —Roland Barthes
}

"Yo, por mi parte, lo que me propongo, y ya en serio, es unir el narcisismo y la fatalidad, que es la muerte.

Cualquiera de las dos explica la juventud."

-Andrés Caicedo, Mi cuerpo es una celda

"So scared of getting older, I'm only good at being young" —John Mayer, "Stop This Train"

La autoficción recoge una variedad de prácticas escriturales en las que encontramos la intromisión, desdoblamiento o puesta en escena de un autor real en el discurso de un texto. Este fenómeno puede variar desde un discurso novelesco bombardeado de referencias al autor; o bien podríamos considerar su converso: textos plenamente autobiográficos enredados con instancias de ficcionalización. Escribir sobre uno literariamente, sin embargo, se ve más en autores noveles que quizás no tengan los referentes suficientes como para escribir fuera de su propia historia y desarrollo. Esto no significa que todo/a autor/a escoge escribir sobre sí mismo/a, sino que para muchos, es el material que más a la mano se tiene y, en algunos casos, el cuerpo al que más se le puede sacar provecho. Éste es el caso de Andrés Caicedo, escritor caleño que nace en 1951 y 
se suicida a los veinticinco años. Su carrera pública como escritor no pasa de los diez años, pero acorde a su filosofía de vida, lo mejor que pudo haber hecho era dejar obra, y nos deja un legado prolífero que hoy día está ganando atención fuera de su Colombia natal. Al enfrentar la desaforada urbanización que eventualmente desemboca en el mundo posmoderno, Caicedo perece tras una vida corta pero explosiva, sobrellevado de angustias y adicciones y subibajas que, sumado a su monstruosa capacidad para representar(se) en su escritura, produce una de las obras más originales y más adelantadas de su época.

En el presente estudio analizaremos las múltiple gradaciones en las que Caicedo logra concebir, elaborar y difundir su escritura como una extensión de sí mismo, como una vida ficcionalizada a varios niveles diegéticos. Para ello, recurriremos en gran medida a La autoficción. Reflexiones críticas (2012), compilado por Ana Casas, cual sirve de marco teórico para entender esta modalidad de la (no)ficción tan advenediza. Como Casas explica, en 1977 -el mismo año que Caicedo termina su vida- se publica Fils, y su autor "Dubrovsky apuesta por la existencia de un género mestizo en el que, contradiciendo a Phillipe Lejeune, sí es posible que un héroe de novela lleve el mismo nombre que el autor: es decir, que el pacto de ficción sí es compatible con la identidad entre autor, narrador y personaje" (9). Casas establece que "la narrativa autoficcional permitirá al autor hablar de sí mismo y de los demás con mayor libertad... [y] que ofrecería al escritor la oportunidad de experimentar literariamente a partir de su propia vida, de ser otros y uno mismo a la vez" (17). El/La autor/a toma, entonces, la libertad de usarse a sí mismo/a, su psiquis y/o su entorno-cuan variada pudiera ser-como el barro a ser moldeado en ficciones, en versiones alternas de su vida. Esto implica la intromisión directa del/a autor/a real en el discurso del texto, cualquier faceta de su personalidad o su historia. Cuán fuerte sea esta influencia es precisamente el foco del debate: si un texto debería ser digerido más en clave autobiográfico o ficcional. Son las sutilezas del término que en práctica complejizan el análisis (y a veces hasta la comprensión) de un texto: 
El propio término autoficción alude, pues, a un hibridismo que admite todas las gradaciones $\mathrm{y}$, por ello, resulta extremadamente lábil como concepto. Bajo él encuentran acomodo textos de muy diversa índole, que tienen en común la presencia del autor proyectado ficcionalmente en la obra (ya sea como personaje de la diégesis, protagonista o no, o como figura de ficción que irrumpe en la historia a través de la metalepsis o la mise en abyme), así como la conjunción de elementos factuales y ficcionales, refrendados por el paratexto. Sus márgenes son, en consecuencia, la autobiografía, con respecto a la cual un buen número de críticos considera la autoficción una variante o deriva posmoderna, pero también la novela, incluyendo sus manifestaciones antirrealistas. Ese es el amplio espacio que ocupa la autoficción. (11)

Como lectores, entonces, desde el inicio, partimos con la amplitud que conlleva la escritura autoficcional. Varios teóricos coinciden en que un/a lector/a tendrá que realizar "dos pactos de lectura en principio excluyentes (el pacto autobiográfico y el pacto novelesco)" (Casas 22), ya codificando en sí una pragmática de una lectura doble. El primero, según Lejeune, presupone un principio de sinceridad por parte de quien escribe, que los hechos hilvanados en un texto autobiográfico son verídicos, y para ello, se requiere una coincidencia entre el autor, el narrador y el protagonista. El segundo, sin embargo, implica lo contrario: que un texto es artificio y poco más, que lo aquí narrado no está basado en hechos reales, que un texto, en cuanto salga de manos del/a autor/a, deja de ser parte de él/ella.

Entonces, ¿cómo nos ordenamos al enfrentar una lectura? ¿Hacia dónde y en qué ángulo apuntamos el lente? Resulta que no debemos amarrarnos tanto a la teoría sobre el asunto, ya que "hay una cierta disparidad con los criterios, las nomenclaturas o las características que definen y delimitan la autoficción”, y un término como "mestizo" sólo apunta a su apreciación en el mundo académico (Casas 22). Muchas de las definiciones a las que se refiere Casas -y a los que nos 
referiremos en varias instancias a lo largo de este estudio- parten de técnicas y estrategias del autor que pudieran apuntar hacia una referencialidad con el autor real; en este sentido, estos críticos elaboran su análisis de las partes al todo.

Nuestro análisis, sin embargo, partirá desde el todo hasta sus partes comenzando con identificar la intencionalidad del autor en elaborar la autoficción como género (como podemos discernir de la cuentística del puertorriqueño Manuel Ramos Otero, incluso iterado por el autor mismo) para entonces jugar con las gradaciones de la ficcionalización de su biografía, o la autorreferencias es sus ficciones. Esta doble lectura se propone como un acercamiento hacia textos plenamente autoficcionales, en el cual el lector perspicaz entra con la intención de acercarse a un texto en el plano novelesco/ficticio a la vez que explora las complejidades de las referencias autobiográficas. Para ello, debemos precisar que una doble lectura autoficcional no debe limitarse a una mera comparación entre su biografía y sus textos literarios (aunque, en el acto, ya se comienza, o se anticipa, una lectura autoficcional). ${ }^{1}$

En esta coyuntura valdría la pena comentar "La muerte del autor", según nos explica Roland Barthes pocos años antes de que Caicedo comenzara su carrera. Como seguiremos elaborando, nuestro autor no compone su escritura como un "lugar neutro... en donde acaba por perderse toda identidad, comenzando por la propia identidad del cuerpo que escribe". Todo lo contrario: Caicedo concibe su escritura como el espacio propicio para la elaboración de su propio cuerpo e historia, sus letras como una extensión indispensable de sí mismo - no como cualquier otro sujeto que escribe, sino más allá, como una extremidad que es indesligable de la historia del desarrollo de su personalidad, es decir, una autoficción. También proponemos analizar las matices, pero en el acto

${ }^{1}$ Está de más decir que un/a autor/a se nutre de su propia vida para escribir; ese detalle es obvio. Cuando se propone leer un texto en clave de autoficción, se debería proponer identificar también la intención del/a autor/a: si se utiliza la autoficción como estrategia del/a autor/a, como un recurso diegético para lograr una multiplicidad de fines (pensemos en lo que ocurre con Vargas Llosa en La ciudad y los perros o Dante en La divina comedia), o si para desdoblarse el/la autor/a dentro (y fuera) de la página, para que el referente del autor real influya en la lectura, y/o viceversa. 
de escribir y publicar (o verse publicado incluso después de la muerte), Caicedo mismo se vuelve "dueño" de su propia obra e incide en controlar o más bien modular la interpretación de sus textos (como veremos en Mi cuerpo es una celda), a la vez que elabora su propia leyenda sobre sí mismo como autor, como ente que se desarticula (no tanto muere) en cuanto escribe. En vez de aportar a una "cultura letrada" general de su generación (la del Boom latinoamericano, plenamente, y más aún en la Colombia de los años sesenta y setenta) decide crear su propio marco referente y su propio espacio cultural (como habremos observado en Calicalabozo), un espacio urbano que hiede en su entorno tropical, que es, en realidad, una rearticulación del laberinto interno de su psiquis que, también, es inseparable de Caicedo mismo, que vive y ruge menos si no tenemos al autor acompañándonos en la lectura.

Si comenzamos una lectura de Caicedo en clave de autoficción, encontraremos al autor ficcionalizado en la totalidad de su obra, cual crea una incapacidad de categorizar sus textos, algunos más novelescos y otros más autobiográficos, en una sola modalidad o categoría. También dudamos que ése sea el punto. Podemos disecar por partes las distantes gradaciones, sutilezas y contradicciones que añaden rizos ficticios a su escritura y a la historia de su vida tan ampliamente homenajeada (y, si lo admitimos, ya ficcionalizada). Esto se suma a una amplia variación en la manera de acercarse a uno mismo a través de palabras, produce distintas maneras en que las mayores virtudes y temores son extrapoladas en novelas complejísimas o minimizadas en la claustrofobia de espacios urbanos, y apunta a la espantosa capacidad que el autor tuvo en vida para contemplarse como una roca en la mano, virado a varios ángulos bajo variada iluminación, para eventualmente desembocar en su fin prematuro.

Como nos explican en “¡Éste (no) soy yo?” (2007) por Manuel Alberca, profesor y crítico español que ha dedicado múltiples investigaciones al género autoficcional, "la identidad del autor no debemos entenderla como sustancia o esencia, sino como su representación o figura, aprensible directamente en el texto narrativo" (89); es decir, que "ha dejado huellas inequívocas de sí mismo" y esa 
ambigüedad no se puede ignorar, una desconexión que sí es posible en una novela (90). El/La autor/a coincidirá con los personajes en sus descripciones y sus pensamientos, utilizará la máscara de la ficción para exponer sus opiniones, dejará huellas que efímeras en la arena serán inmortalizados en su literatura—tan así que resultará obvia una correlación entre la vida real del autor y el discurso. Esto le da pie a Caicedo para decir la verdad a la cara del espectador-parecido al monólogo de la protagonista en el comienzo de su filme Angelita y Miguel Ángel (1971)—y comunicar verdades que jamás pudo exteriorizar en vida para elaborar de los discursos más originales y adelantados de su época:

El yo autoficticio es un yo real e irreal, un yo rechazado y un yo deseado, un yo auto biográfico e imaginario. Todos los yos caben en él: el yo mitómano y el yo verdadero, el megalómano y el ecuánime, el consciente y el inconsciente de su propia invención. No renuncia a nada, pues está abierto a toda clase de metamorfosis personales y de suplantaciones fantásticas, que le convierten en otro sin dejar de ser él mismo, es decir, sin dejar de saber que yo es y no es otro. En el terreno de la autoficción, la contradicción se vuelve, además de verosímil, natural...” (92)

Alberca alude, entonces, a la pragmática de la escritura autoficcional, el juego y la ambigüedad desde un inicio contradictorio que un autor asume al usarse como inspiración. Puede inventarse un universo entero para sí mismo-o, en el caso de Caicedo, un laberinto del cual nunca pudo encontrar salida. Sin embargo, al idearse su cárcel, elabora también sus escapadas, sus noches infinitas, y una utopía caleña que, bajo el marco que propone Alberca- -la autoficción se convierte en una especie de espacio de promisión para el individuo, en el que serían aceptables todas las liberaciones y caprichos personales, todas las identidades, tanto las reales o vividas como las imposibles o soñadas" (95) — 
puede existir en su ficción sólo para derrumbarse en un espiral babélico, desmoronarse en la medida que Caicedo morivivía.

No obstante, algunas definiciones de Alberca resultan limitantes. En sus análisis se presupone un principio de identidad característico de la autobiografía clásica que en la contemporaneidad no es tan exigida ni en la autobiografía y que no debe ser prescrita para los trabajos autoficcionales. También parte de una literatura exclusivamente española y novelesca, cual excluye por completo el carácter paradójico de la ciudad tropical americana- "Cali en su calidad de metonimia narrativa del gran teatro del mundo moderno, con su melancolía y su fiesta" (Fuguet 206) — con tanta vida que arde y tanta muerte que acecha, y textos no narrativos que sí proyectan desdoblamientos y fabricaciones de la vida del autor.

\section{Cómo escapar la celda del cuerpo: La (auto)biografía caicediana y el lente de}

\section{Fuguet.}

Como se discute en el marco teórico, notamos una presunción de que las referencias autobiográficas son las que resultan hilvanados en un discurso novelesco; sin embargo, Mi cuerpo es una celda (2008) logra lo opuesto: se insertan ficciones autorreferenciales en los textos con los que sí se establece un pacto de identidad. Si consideramos que Caicedo escribe cada sección que compone su (auto)biografía a finales de los años sesenta y principios de los setenta-una minuciosa colección de textos en orden cronológico (pero poco lineales) que incluye epístolas, versificaciones, glosas cinéfilas, ejercicios de autorretrato, prosa poética, selecciones de diario y hasta textos plenamente autoficcionales-hay que dudar de "la autenticidad y sinceridad que [a la autobiografía] se le supone" (Casas 15), ya que para esa turbulenta época se comienza a dudar la idea de una sola verdad establecida para cada individuo en la sociedad, de una sola manera de existir y de verse a uno mismo en el espejo. La 
turbulencia política y fervor juvenil en la década de los sesenta en América Latina es evidencia de ello, y Caicedo resulta de sus testigos más eficaces.

Caicedo decide romper con esa herencia sociohistórica en el torbellino cultural de su época, se desemboca en espacios cinéfagos y macabros de la ciudad que habita y que crea para sí mismo. Cuando una sociedad (o un individuo) se encuentra desajustado y fragmentado por una crisis de identidad, como le ocurre al autor en Mi cuerpo..., el sujeto recurre a la escritura de sí mismo, de su propia historia, para definirse y superar la crisis. Desde la primera sección de $M i$ cuerpo ..., cual recoge desde 1966 hasta 1972 -estos años coinciden, también, con el grosor de los cuentos de Calicalabozo (2008)- ya vemos un Andrés desconcertado, fragmentado en distintas identidades que la gente conoce pero que no son el verdadero Andrés, ficciones externalizadas de y por Caicedo que, según él mismo, no concuerdan con la imagen interna que tiene de sí mismo: "Pero digo yo, me pregunto, ¿cuál Andrés? ¿A quién fue que conociste acá en Cali? ¿De quién y cómo es que te acuerdas?” (Fuguet 33). El autor sufre para aquella época una serie de enredos en su vida personal -relacionados con el trato y la crianza por parte de sus padres, sus vicios y sus locuras como escritor y como drogadicto, y la depresión suicida que lo mantiene solitario y retraído por años- que hacen dudar de su identidad, de su rumbo en la vida, y encuentra salida mediante sus textos. Tal como los países que quieren revaluar su historia y elaborar un discurso distinto que explique su desarrollo en la historia, al tener ese vacío en su memoria de quién era aquella persona/figura pública que había fundado el muy concurrido Cineclub de Cali -y que en un futuro lanzaría la revista independiente de crítica de cine Ojo al cine-Caicedo necesita recurrir al espacio interior, a su propia soledad, para redescubrir aquellas facetas que ha olvidado y elaborar el desarrollo de su personalidad -o rellenar aquellos espacios con sus pensamientos más tenebrosos, más perversos, transformados en palabras, en literatura. Sin embargo, como ocurre con las historias oficiales de los países, no es inusual encontrar que el discurso estire o tergiverse lo que realmente ha ocurrido. 
A nivel del discurso profundo del texto, es como si Caicedo elaborara su propia autobiografía a lo largo de su vida, instancias enterradas como minas terrestres en sus cartas y su crítica de cine para que sus lectores/as descubran en el camino, ya que el autor "trata de comprenderse a sí mismo [y] selecciona determinadas facetas de su experiencia haciendo que estas desemboquen en el tiempo presente y contribuyan a dar una imagen coherente de su vida", implicando en el acto un tipo de censura (Casas 15). La idea de Mi cuerpo... como una ficción parece más factible si recurrimos a sus paratextos, estrategia sugerida por Casas, y reconocemos la presencia de Alberto Fuguet, escritor chileno contemporáneo, a quien se le atribuye la "Dirección y montaje" -dos conceptos imprescindibles del género del cine que tanto cautiva a ambos autores. En la contraportada adquirimos el pie forzado para la lectura: que el libro que tenemos en mano "quizás sea una novela, una novela de no ficción”. Esta categorización, aun ambigua, puede determinar $\mathrm{y}$ hasta prejuzgar su interpretación.

Una novela de no ficción es una paradoja en sí misma, como parte de aquella "tendencia contemporánea y posmoderna a la hibridación" (26), muy anticipada por Caicedo en su tiempo, y apunta hacia la autoficción; el término hasta lo sugiere. Como Fuguet mismo lo define, "Autobiografía es el recuento de los hechos de una vida contada por la propia persona"; la obra "necesariamente tiene que ser escrita por la persona que ha vivido esa vida", pero no encontró que el libro "tuviera que haber sido compilado/montado mientras el autor estaba vivo" (Fuguet 257). A la ya aludida "ficcionalidad" de la autobiografía, entonces, se le suma otro plano ficcional, el de Fuguet, quien tiene su propia interpretación de la vida de Caicedo_- "Es la idea del cinéfilo como mártir, el post-adolescente latinoamericano alienado con Hollywood, el solitario que se comprometió con la pantalla mientras todos solidarizaban con la causa... el link perdido al siglo XXI...” (262)—y su propio criterio respecto a los textos. Fuguet lo complica aún más todavía: 
CATEDRAL TOMADA: Revista literaria latinoamericana / Journal of Latin American Literary Criticism

“Que enloquezcan mis personajes, no yo": Instancias de autoficción en la obra de Andrés Caicedo

[N]o quería hacer una biografía... entendí que quizás lo que correspondía era hacer algo cinematográfico... porque había algo inherentemente visual en su manera de concebir su vida y en la manera como se comunicaba con el mundo... De ahí la idea del documental. Un documental narrado en primera persona que certificara en forma fragmentaria lo que él mismo vivió, sintió y vio. No tenía a mi sujeta ni cerca ni vivo, pero había cartas, diarios, poemas, críticas de cine y material que se negaba a ser catalogado en ese bolso. (258)

Un buen equivalente para esta (auto)biografía es un documental, ya que posee el carácter puramente mimético del cine y usa imágenes vivas y sonoras para hilvanar su propia tesis respecto a un tema; en otras palabras, un ensayo de imágenes o, si se quiere, una novela de no ficción. El mismo Caicedo nos cuenta que "[e]l concepto de que el cuadro, el fotograma, es la ventana al mundo, es de hecho un pensamiento hermoso, liberador. En esa vida de la pequeña burguesía me gustaba pensar en que observando un film podía tener acceso a hechos recónditos de la vida real, y a sucesos que tal vez nunca llegaría a experimentar, y que para eso no necesitaba más que dos movimientos: salir de la casa y sentarme en la butaca, callado, a ver" (Fuguet 105-6).

Para entender la vena cinematográfica que corre en toda su producción literaria, recurriremos lo que nos explica Llorca: que "[u]na película en su configuración formal es una sucesión de fragmentos de tiempo y espacio... en el montaje tradicional los planos establecen entre sí múltiples asociaciones espaciotemporales. Estas micro-asociaciones van construyendo un tiempo y un espacio global imbricados en la historia del film" (376). Atribuimos el mismo valor a los textos en Mi cuerpo..., altamente cinematográficos, para entender que se escriben con la misma intención, de adentrarse en hechos y sentimientos que Caicedo jamás podría sentir, pero en los cuales encuentra -además de en la soledad (¿aliviadora?) que su escritura le produce- la calma y la tranquilidad que tanto 
añora: "No veo otra forma de aproximarme a un comprendimiento de por qué nací bajo el ala de la melancolía y de esta tristeza que me mata. Ahora escribo para calmarme y para buscar un orden" (Fuguet 131).

Ya que observamos la mezcla de cine-virtual y ficticio por naturalezade los textos a lo largo de Mi cuerpo... y también el carácter fragmentario de psiquis del autor, podemos concluir que la tendencia cinematográfica en su escritura sirve para inmortalizar el espacio que a Caicedo le toca experimentar, proveerle permanencia a aquel sufrimiento tal como las imágenes de una película pueden inmortalizar un espacio y servir como documento de una época específica, ya que el "espacio cinematográfico es pues un lugar vivo, figurativo, que añade a su aparente tridimensionalidad el tiempo, variable por la cual la cámara explora con nosotros una realidad estética, enriquecida por la historia que nos narra. Es indudable que la poética del cine de ficción aporta, con el relato, una nueva dimensión que supera lo documental" (Llorca 374). Fuguet sugiere lo mismo: "Mi impresión es que aquí, en este libro, Caicedo demuestra al menos dos cosas: que no tenía miedo de usarse como su material principal y que su no ficción es tan impactante - o acaso más - como su ficción" (260). Caicedo en vida valora sobre todo el cine de ficción, cuya arte no se sustenta en su calidad mimética exclusivamente, y pretende añadirle a su vida pinceladas ficticias para elevar el significado de la retahíla de males que padece y así adjudicarle sentido a la angustia que lo acompaña en su largo viacrucis.

Sin embargo, "aunque una obra se parezca a la realidad, no está constituida sólo por ella, el estilo es la huella que da cuenta de la subjetividad del artista. Todos estos elementos se ven forzosamente penetrados, entre otras cosas, por los referentes culturales que en su momento posee el creador" (Llorca 375); en este caso, el creador, también, resulta ambiguo. Al parecer, una recopilación de textos autobiográficos no produce necesariamente autobiografía-y aunque Fuguet considere "tema secundario" el hecho de que Mi cuerpo... sea considerado o no una autobiografía, para este estudio lo consideramos un asunto indispensable. El hecho de que el libro no haya sido concebido por Caicedo lo 
podría descalificar como autobiografía - pero no tanto. Los textos que Fuguet considera ejercicios autobiográficos, para otro/a lector/a que quisiera leer $M i$ сиегро... en clave de autoficción, podrían ser leídos como ejercicios autoficcionales, otras personas del mismo Andrés Caicedo, intentos del autor de escribirse a sí mismo partiendo de una multiplicidad de filmes, cartas, divagaciones y digresiones. Por ejemplo, en varias instancias del texto, Caicedo recurre a la tercera persona para describirse a sí mismo como "el hijo hombre que nunca creció, nunca consiguió mujer y envejeció antes de cumplir los 20 años"; el que "escribió el grueso de su producción cuando aún su mente no estaba formada"; el que quisiera tanto salir de su encerramiento pero "hablar no puede, no sabe hablar, es mudo como un niño" (Fuguet 85). Aquí apreciamos sólo un rastro de la leyenda de Caicedo en su literatura, aquel Peter Pan que nunca quiso crecer, que sí crece físicamente pero que (Caicedo piensa, Caicedo escribe) se queda atascado en una adolescencia eterna.

Mi cuerpo... contiene, además, textos que Caicedo no necesariamente escribe con la intención de publicar-aunque Fuguet haya debatido las implicaciones éticas de publicar textos almacenadas por el autor en grandes baúles que recogían polvo y memorias en la casa de sus padres - aunque Caicedo mismo haya dicho "en conversaciones con su familia y amigos... que lo suyo no era un ejercicio privado" (265). Contiene incluso textos que son elaboraciones de Fuguet y que nunca fueron concebidos como aparecieron en el libro: "Aquellos escritos que aparecen como apuntes o posts o anotaciones en un diario de vida son un invento mío a partir de muchas frases de Andrés que aparecían en largas cartas centradas en temas ni cinéticos ni personales" (264). Fuguet funge, entonces, de autor implícito en el sentido de que sería, podría ser, Caicedo treinta años después, recontando la turbulencia de aquellos tiempos, si no hubiera logrado su suicidio con sesenta senocales aquel 4 de marzo de 1977. Responde a aquellas preguntas que tal vez Caicedo pudiera haber contestado con el pasar del tiempo: ¿quién es?, ¿en qué o quién se está convirtiendo?, ¿hacia dónde va aquel personaje que llaman Andrés, de quien tanto hablan, de quien tanto leen? Andrés 
no sabe quién es, no entiende quién escoge las palabras que salen de su boca y sus manos. “¿Quién era yo?” él se llega a preguntar. ${ }^{2}$ Hallamos aquí una motivación, una fuerza motora, para la elaboración de la autoficción como género.

Es imposible saber a ciencia cierta si varios de los aspectos del montaje del libro - entre otros, el contenido, su orden y temática; la estructura profunda y sus ambigüedades contradictorias; la exclusión y la presencia de algunos textos; la estética de la editorial y del libro como tal-serían totalmente acordes con la historia que Andrés hubiera querido contar de su vida. "Caicedo escribía a sí mismo", cuenta Fuguet (263), cual sugiere las múltiples ediciones, añadiduras, extirpaciones y modificaciones que pasarían los textos (y Caicedo mismo) antes de llegar al lector. Y no es por desprestigiar ni el montaje ni el valor del texto, cual consideramos invaluable, sino para constar que esta (auto)biografía podría ser leída como una ficción. Por cierto, si nos adherimos a categorías definitorias, el texto de Caicedo (aquí recopilado por Fuguet) cabe perfectamente dentro de la definición de autoficción según Duborovsky: que "el pacto de ficción sí es compatible de nombre entre autor, narrador y personaje" (Casas 9). Por otro lado, Arnaud Schmitt "propone un nuevo término, autonarración, el cual agruparía dos géneros: la autobiografía y la novela autobiográfica... [Ésta] no buscaría, por lo tanto, evitar la confrontación con lo real ni protegerse tras la máscara de la ficción, sino, todo lo contrario, su objetivo sería decir lo real pero adoptando una forma literaria" (Casas 31-2). Un ejemplo podría ser al adoptar la forma epistolar, "en donde se puede encontrar, después de mi muerte" — escribió Caicedo—, "algo de lo mejor que he escrito" (Fuguet 186). Abre pie para la literalidad de una narrativa autobiográfica, una ficción (o varios niveles de ficcionalidad) sobre el yo, y "sobre esta base el autor narra episodios que no tienen que ver tanto con la

\footnotetext{
${ }^{2}$ Partiendo de un análisis de la novelística de Unamuno, Alberca establece: "La necesidad de inventarse a sí mismo en sus personajes o de «hacer la novela de la vida», como de manera paradójica dirá, tiene su origen en la convicción de que no es posible el conocimiento directo de sí mismo, sino objetivándose en otro, en una criatura de ficción” (93). “¿Quién soy yo? ¿El que los demás piensan que soy, el que creo ser, el que soy en realidad?" se cuestiona también Unamuno (94).
} 
CATEDRAL TOMADA: Revista literaria latinoamericana / Journal of Latin American Literary Criticism

“Que enloquezcan mis personajes, no yo": Instancias de autoficción en la obra de Andrés Caicedo

verdad-los hechos verificables, objetivos-, sino con su verdad íntima $\mathrm{y}$ subjetiva" (Casas 31-2).

Con esto en mente, podemos leer el texto y rebuscar sus claves, teniendo siempre en mente desenterrar las partes de su cuerpo que Caicedo ha escondido en sus textos más íntimos. También proponemos añadir otra dimensión al lector caicediano: una lectura invertida, ya que algunos Bonus Tracks, cuales consideramos las porciones más autorreferenciales, interesantemente, se encuentran justo al final de Mi cuerpo... Así también leeremos su obra en el resto del estudio, desde sus últimas publicaciones post mórtem hasta los que publica en vida, para ofrecerle al/a lector/a una forma de conocer al autor desde su final trágico hasta sus primeras intentonas en la escritura, como usualmente ocurre con un/a primer/a lector/a de Caicedo, quien se acerca desde su última publicación, adentrándose por los sesos hasta alcanzar la médula — es decir, del todo a sus partes.

En el Bonus Track 3, aprendemos que para su vigesimocuarto cumpleaños, su madre se ofreció a sufragarle una reimpresión de su primer libro, $E l$ atravesado, y Caicedo "escribió [un texto] acerca de sí mismo, de su valor y su lugar en la literatura colombiana", cual fue añadido a la contraportada (Fuguet 294); una vez más recurrimos a los paratextos. No obstante, este mordisco biográfico, la última sección de texto en Mi cuerpo..., no aparece firmado por Andrés Caicedo, sino por el escritor Jaime Manrique Ardila, quien confesaría años después que aquella "generosa contraportada" no era de su autoría. Si acaso, éste sería de los textos más autobiográficos en su corpus enceldado, según Lejeune: es una narrativa retrospectiva centrada en el desarrollo de la personalidad de quien lo escribe; tampoco es la primera vez que un texto escrito en tercera persona pudiera ser considerado autobiográfico (Casas 10-1). Si se lee presumiendo la autoría de cualquiera de los dos autores, sin embargo, se nota la disposición a contar una leyenda urbana sobre Caicedo, a nadar sobre la superficie de lo que Caicedo considera de sí mismo y su incipiente producción literaria: "su caso era, indudablemente, un espejismo. Pues, ¿cómo podría este jovencito 
inseguro, un tanto ridículo y a la vez pagado de sí mismo, escribir textos sobre mínimos problemas de adolescencia que tuvieran significancia internacional?” (Fuguet 295). Y aunque sí funja como un relato que destaque hazañas de su carrera literaria hasta aquel entonces, también elabora una especie de ficción acerca de su vida, una historia para ser contada sobre aquel personaje extraño que era el autor de aquel libro que tuviera un/a lector/a en la mano, una imagen que alude tanto a su contenido como a su autor atorado "en una aterida adolescencia" en el cual la precocidad sólo podría desembocar en la autodestrucción (295-6). Conforma parte del imaginario caicediano en Colombia, la del roquero que "con orgullo suicida [exhibía] una imposibilidad total para integrarse a toda clase de grupo", y quería que el lector se adentrara en su literatura prejuiciado, con una visión no necesariamente errónea, pero sí falsa-por el hecho de que aparece "firmado" por Manrique-aunque no tanto. En otras palabras, Caicedo mismo no sólo se adueña de una posible interpretación de su texto, sino también intenta controlar una lectura de su propia vida incluso después de su muerte, acto que Barthes considera innecesario en el proceso de lectura y análisis. Caicedo, entonces, teje una ficción sobre sí mismo que exige a la vez un pacto extraño, sumamente ambiguo, con su lector-una modalidad relativamente sencilla de la autoficción.

Resulta interesante, entonces, la localización de este texto en Mi cuerpo...: justo al final, sucedido sólo por los "Agradecimientos" (de Fuguet, no de Caicedo), como si uno sólo pudiera aprender verdades de Caicedo cuando ya era demasiado tarde - tal como lo fue para Fuguet, y para nosotros, sus lectores/as contemporáneos. Estas dos páginas proveen claves tanto de su vida como de su obra, sucesos y decepciones y conductas y adicciones que desembocan en su vida y en la de sus personajes, e incluso alude a las interrogativas de un/a futuro/a lector/a - alguien como Fuguet $u$ otros críticos que valoran a Caicedo hoy día como un adelantado desalmado en la literatura colombiana-cuando cierra con: "su trágica defenestración y descorazonamiento nos dejan sin respuesta la 
cantidad de preguntas que teníamos para hacerle" (296). ${ }^{3}$ Ya el autor alude a su prematuro fenecimiento y el vacío que quedaría, a la huella que dejaría con su crítica y su literatura, a sus más grandes e insuperables derrotas, al espiral descendiente del cual jamás halla salida - todo cual si fuera una profecía autorrealizada que deja al lector paralizado frente al cuerpo de Caicedo enjaulado en aquel libro, leyendo con aplomo como si atestiguara el accidente de tren más horrendo y hermoso de la historia.

Si seguimos retrocediendo en el tiempo, el Bonus Track 1 trata de partes de un cuaderno que su psiquiatra recomienda que escribiera los treintinueve días que se encuentra interno en la Clínica Psiquiátrica de Santo Tomás de Bogotá, un especie de "diario de vida o, mejor dicho, un resumen de ésta" (272), en el que aparecen detalles claves para el entendimiento de su(s) persona(jes). Ahí aparecen explicados, por ejemplo, sus impresiones acerca de Clarisol y Guillermo Lemos, "dos niños súper precoces y perversos" (274) que eventualmente adentraron a Caicedo en el mundo de la droga y el trasnocheo rumbero-iniciativas que, "debido a [su] impresionable naturaleza" (280), Caicedo termina acomodando a su propio repertorio emocional, y que terminan formando parte íntegra de su temática como escritor a lo largo de su carrera. Como nos explica Alberca, "el yo de las autoficciones oscila entre la carencia de una identidad propia y la necesidad de auto-invención, para concluir en muchas ocasiones que el autoconocimiento es imposible" (96). Es con esta iniciativa de las drogas-y de la infancia en general, hasta los que (como Caicedo) se niegan a crecer-en explorar conciencias alternas que se funda su manera particular de vivirse otras vidas a través de sus textos literarios, no tanto para explorar un mundo ajeno al suyo, sino para trasvestirse con otras máscaras y encontrar solaz en sí mismo, en su soledad

\footnotetext{
${ }^{3}$ Parece ser la misma interpretación que Fuguet tiene del autor, al cual hemos aludido; es decir, Caicedo cruza esa "cuarta pared" de su texto para incidirse en la mente de Fuguet, quien decide entonces incidir en el lector a inicios de Mi cuerpo... Así, las palabras de Fuguet sirven de puente entre el lector contemporáneo y la obra de Caicedo, tanto como las palabras de Caicedo (su autoficción de contraportada) une sus textos con su propia vida.
} 
cúbica, en la manera particular de sus personajes en continuar con su vida a pesar del tormento por el cual vadeaban a diario.

Consideramos imperativo, en este punto, recurrir al cine para analizar $M i$ cuerpo... más a fondo. Caicedo también nos deja claves en su crítica de cine, cual conforma el grosor de su producción literaria—ipero qué hacen análisis cinematográficos en una (auto)biografía? ¿Por qué incluirlos en un libro cuyo lector presupone una referencialidad inmediata al autor del texto? Es porque Fuguet sólo incluye crítica que sí tienen resonancias con la vida del autor, que sirven de inspiración tanto para su vida como para su literatura. Estos ensayos, las (no) ficciones en su (auto)biografía, contienen análisis y sentimientos ineludiblemente referentes al sentir del autor-es decir, estas ficciones son autobiográficas aun cuando no las son, aun cuando los textos (y las películas comentadas) suponen ser ficción, especialmente si se considera su yuxtaposición a sus cartas, en las cuales se desdobla de forma más directa, más íntima. Parecen ser más desdoblamientos, más confesiones, más reiteraciones de las angustias que Caicedo vio en su vida y que vio proyectada en ficciones.

Nos limitaremos a un breve recorrido de la crítica de cine que aparece en Mi cuerpo... Comenta de American Graffiti (1973) un sentido de nostalgia en el film hacia una juventud y una infancia perdida que Caicedo reproduce en su imaginario caleño, como veremos más adelante; y el film "parte del hecho de que la juventud es una institución, tal vez la más importante de la sociedad estadounidense" (Fuguet 114). Los personajes que denominamos ficticios en la obra caicediana son una extensión del sentimiento de la juventud caleña de los años sesenta, efigies que representan rebeldías caóticas "que contradicen los patrones de identificación con su cultura" (Carvajal 140), así elaborando una crisis de identidad individual y colectiva, terreno fértil para la autoficción. Por otra parte, Caicedo comenta que los films de Bergman presentan artistas como creadores - tal como él mismo presenta en sus cuentos a escritores jóvenes en momentos de creación literaria-; los films también exploran las complejidades de "la naturaleza femenina" y escribe que "la mujer es para Bergman, como la 
ventana al mundo desde donde se puede contemplar, con serenidad y paciencia, los recónditos intersticios de un alma atormentada"-lo que podría explicar por qué pudo haber escogido a María del Carmen Huertas como protagonista de su novela más famosa-; y de manera sumamente autorreferencial, comenta que

las angustias podrán ser muchas, pero jamás ninguna podrá igualarse a la del hombre que pretendiendo ser testigo de su época expresándose como mejor sabe, se regodea por extrañas razones de orden, creyendo hacerse por fin a un abismo sin fondo, por orgullo y egoísmo, en la imposibilidad creativa" (Fuguet 176-7).

También nos interesa un ensayo sobre La historia de Adèle H. (1975), en específico porque el personaje de Adèle - la que en vida fue hija del novelista decimonónico Víctor Hugo-personifica un híbrido entre Caicedo y María del Carmen Huertas, una fundición complejísima que retrata el personaje de Adèle cual si pasara por las angustias que Caicedo relata en sus cartas acerca de Patricia Restrepo, "un amor que tal vez ni fue buscado, pero que llegó de sopetón e inmediatamente segó todo interés, todo estímulo, toda otra inclinación en la vida" (198). Entre otros aspectos, relata del film la manera en que los personajes principales se mandan cartas exhaustivamente, seguido por la angustia inmensurable de tener que esperar una carta, por lo cual recurre a andar sin rumbo fijo para así matar el tiempo, y finalmente aparece la carta sólo para abrir paso a un comentario del autor sobre alguna situación política. Esta descripción de la estructura sencilla del film es un reflejo "ficcionalizado" de su relación tempestuosa con Patricia, de la estructura profunda de sus cartas más amorosas. 


\section{Como amarrarse a la celda de la ciudad: La "ficción" caicediana y el laberinto de Cali}

Hemos analizado varias maneras en que la autobiografía-como género literario, como modalidad o estrategia del/a autor/a — es redefinido y revaluado en tiempos contemporáneos (por no decir posmodernos), luego trabajado por Caicedo y finalmente recopilado por Fuguet. No sería tan difícil, entonces, adentrarnos en sus ficciones y de ahí tomar nota de las intromisiones del autor real. De la obra de Caicedo el texto en que más experimenta con la autoficción es en Calicalabozo (2008), publicado en este siglo unos treinta años después de su muerte, cuyos relatos escribe entre los quince y veinticinto años de edad, a través de los cuales "se pretende esbozar un calidoscopio de la ciudad vista desde diferentes ángulos por sus jóvenes protagonistas" (Gómez 211). El título alude a la ficcionalización de su ciudad natal, de Cali como vórtice ineludible, y en el libro se nota cómo el autor "toma distancia de la narrativa mimética empeñada en presente con urgencia y énfasis las coordenadas espacio-temporales del mundo histórico contemporáneo del autor" (185). Es decir, que antes de representar la ciudad de Cali, prefiere mejor letrarla, crear una cultura e historia originales más ligadas al cine y la música popular (latinoamericana y estadounidense), elaborar una película de ficción y proyectar tras los ojos del/a lector/a imágenes impresionistas de la cárcel soleada por cuyas puertas abiertas Andrés transita a lo largo de su vida.

Resulta interesante, entonces, la segunda acepción de calabozo según la RAE, "aposento de cárcel para incomunicar a un preso", cual exige la lectura de que fuera insertado y encerrado allí toda la vida — en este caso, a través de su nacimiento en la ciudad y el encierro sobreprotector de sus partes-cual no es el caso: Caicedo visita otras partes de Colombia y hasta viaja a EU para vender sus guiones en Hollywood, aunque no haya alcanzado mayor éxito. La cárcel que Andrés crea en su cabeza (la ciudad) es la que trata de escapar a través de su escritura, en especial cuando se considera el tartamudeo que tanto lo caracteriza 
CATEDRAL TOMADA: Revista literaria latinoamericana / Journal of Latin American Literary Criticism

“Que enloquezcan mis personajes, no yo": Instancias de autoficción en la obra de Andrés Caicedo

en vida, otra manera de explicar cómo su cuerpo es, en efecto, una celda tan opresora como Cali: la extensión letrada por excelencia de la celda de su cuerpo.

Para entender la complejidad de Cali en el imaginario caicediano, primero tenemos que entender la ciudad que le tocó a Caicedo experimentar:

La modernización de la ciudad a raíz de los Juegos Panamericanos crea nuevos hitos y mojones que identifican la ciudad: surgimiento intempestivo de escenarios deportivos, comerciales, nuevas calles y avenidas reemplazan a las anteriores; nuevos usos y gustos alimentan a los transeúntes; nuevos barrios aglutinan los damnificados; esta ciudad va a estar presente con todas sus caras sociales y dudas morales. (Caicedo, Adolfo 189)

Esta modernización desenfrenada, esta acelerada transformación del espacio urbano, además de enajenar al autor y a sus personajes, produce un Cali que entonces es descrito contradictoriamente a lo largo de varios textos en la obra caicediana, una ciudad con una profunda cultura hispánica invadida por el progreso, la urbanización y el gris del cemento espetado directo en el verde de las montañas. Este ambiente gótico y ofuscador, contradictorio por naturaleza con "la visión de la ciudad solar, moderna, alegra y apacible" (187), se puede ver claramente en el cuento "Por eso regreso a mi ciudad" cuando aquel sol y aquella apertura del cielo no contribuye a la sensación de libertad, sino de exposición, de andar revelado y visible ante el mundo, de sentirse constantemente "mirado, acechado por ella" (194). Apreciamos el paralelo que Caicedo establece en $M i$ cuerpo..., cual evoluciona desde una puesta en escena como al comienzo de una película - “La ciudad se llama Cali. La ciudad tiene su río..." (Fuguet 25)—a una nostalgia leve - "me hacen falta las montañas, el cielo zapote o morado recortado contra las montañas, y caminar por la Sexta con la seguridad de que uno se va a encontrar con la mitad de la gente que conoce" (66) - hasta un descontento 
profundo, desconcertante- "Cali no tiene nada más que verle, demasiado el romance tonto, la contemplación de atardeceres, sentirse que se está en familia y terminar en pasarse los días sin hacer nada. No quiero más a esta ciudad, no así de cerca. La amaré de lejos, muy lejos" (128).

Sin embargo, estas gradaciones no son injustificadas: resulta que el espacio urbano es tan complicado y contiene tantos recovecos como la mente humana. Consideremos esta cita:

[E]n la dimensión imaginaria del sujeto sí hay una continuidad entre el yo y la imagen de ciudad. Y esta imagen está dada ante todo porque la ciudad lo golpea, al privarlo de ella, pero ejerce una fascinación que constituye en el personaje una experiencia límite. Más que una queja, el personaje del relato experimenta una fascinación (un encuentro de rostros, de faces) por la imagen de la ciudad, no por la ciudad real... (Caicedo, Adolfo 96)

Esta fascinación (u obsesión bergmaniana) se estira a lo largo de toda su producción; es imposible desentrañar el imaginario citadino de su obra, como tampoco se puede ignorar su presencia real en él, su necesidad insuperable de largarse y desaparecer. $\mathrm{Y}$ antes de comentar los seres que pueblan su ciudad imaginada, hay que considerar el personaje principal, el protagonista de la obra caicediana: Andrés Caicedo mismo. "Cumpliré 22 años en Calicalabozo" (Fuguet 119); es decir, que el autor real también conforma parte de ese universo cerrado que es Calicalabozo, que también su cuerpo ha sido tejido al manto negro de su pueblo natal: "Ciudad de mierda ésta, Calicalabozo, se está y se quiere ir, se va y quiere estar..." (134).

Al leer sus cuentos, no podemos separar, de una parte, a Cali como referente topográfico cargado de historia y cultura enclavada en el trópico, de Cali en cuanto ente narrativo, espacio móvil de voces ambiguas, pero estéticamente efectivas. Esta doble existencia, imaginaria y real-imaginada, resulta relevante en 
la medida en que dicha dualidad se proyecta en la condición misma de los personajes: Cali, al igual que los personajes narrados y los acontecimientos cotidianos narrados, participa del hecho de que lo virtual es parte lo real y viceversa. (Caicedo, Adolfo 187)

Esta ambigüedad respecto a la ciudad es una de las varias contradicciones que Casas considera característicos de una autoficción, una imagen real pero tan fragmentada como lo es ficcionalizada. "Esta ciudad me aprisiona e intenta destruirme", escribe (Fuguet 132). Pero una ciudad no tiene la capacidad real de conspirar en contra de uno, claro está; sin embargo, una mente perceptiva puede identificar (o construir obsesivamente) un discurso que sí, tal como ocurre con el inconsciente.

Todas estas ambigüedades y contradicciones en torno a la imagen de Cali, siguiendo el marco de Casas, se ve aún más problematizado cuando consideramos que "los cuentos de Calicalabozo tienden ante todo a desecar las descripciones detalladas de espacio y de anécdotas unitarias" (Caicedo, Adolfo 197). Podríamos considerar, entonces, que la ciudad de Calicalabozo sirve como otra extensión de Caicedo mismo, un plano en el cual elaborar "un discurso sobre una ciudad adolescente que se teje simultánea y literariamente en los discursos sobre ella como un cuerpo rebelde y fantaseador, una cárcel y un edén, una ciudad abandonadora o propiciadora de férreos lazos afectivos, una ciudad objeto de discuros influyentes y excluyentes del mundo de droga, sexo y rock, convenciones y fantasmas" (191). Estas conclusiones también las comparte Gómez: "Cali es la obsesión de Caicedo, su imagen opresora, el universo complejo por donde discurren sus personajes en busca de la felicidad, el amor o la muerte, La ciudad es elevada a metáfora, sus calles, los lugares de reunión y de rumba; en la mayoría de las oportunidades la ciudad aparece como protagonista privilegiado de la trama discursiva" (210-1). Si no podemos separar a Cali de sus textos, si tenemos en cuenta que Cali(calabozo) es una extensión de Caicedo, entonces tampoco podemos separar a Caicedo de sus textos, lo vemos insertado como protagonista mismo en su obra, una manera muy efectiva en que el autor 
evitaría "morir" en sus textos como propone Barthes. De ahí la idea de que varios de los textos se consideren puestas en abismo (mise en abyme) - un escritor escribiéndose escribiendo, es decir, sujeto que, mientras escribe, elabora una historia de sí mismo como sujeto que escribe—que Casas señala en su texto.

El narrador-personaje se torna una especie de fantasma al que sólo le queda el hecho de ser motivo de una narración que le otorga sobrevivencia, mientras rememora una ciudad posible, pues al no poder transitarla, se ve obligado a imaginarla, mientras la atmósfera de pesadilla, densa busca salida en su discurso. (Caicedo, Adolfo 196)

Esta elaboración casi onírica de Cali, de lo virtual e imaginado que inciden en la realidad, le añade rizos de tensión a la manifestación autoficticia de Caicedo: nos muestra que Caicedo y Cali son uno y lo mismo, que al Caicedo escribir a Cali, se escribe también a sí mismo-y cada defecto que en él encuentra.

Con estas consideraciones en mente, y recurriendo otra vez al mundo del cine, podemos comparar la construcción de Calicalabozo con la estructura onírica de Inception (2010): un sueño (Cali) dentro de otro sueño (su vida), el laberinto inexorable de una ciudad, un universo cerrado construido por él y sólo para él en donde enfrenta varias proyecciones de sí mismo, facetas de su inconsciente que, libres en una ciudad poblado de sombras, de vampiros, deciden atacar al soñador; hasta anticipa lo que en Inception sería el peor destino concebible: quedarse atrapado toda una eternidad en una pesadilla, sin posibilidad de librarse salvo por la muerte: "Rico morir en la madrugada de un domingo. Ya creo que va cayendo la noche. ¿O son ilusiones mías?” (Fuguet 208). Estas “proyecciones”, estas extensiones ficticias de su persona, sugieren "la idea de [una] identidad múltiple o plural... [cual] surge en momentos de crisis y de grandes transformaciones mentales como las que se vivieron en el siglo XX, cuando los sujetos se sienten confundidos a la hora de adoptar sistemas de identidades tradicionales, pues son inciertos o dudosos los patrones de identificación" (Carvajal 139). Como lectores/es perceptivos ante la autoficción, no nos podemos olvidar de lo que nos explica Alberca (92): "El lector debe saber que el yo que habla o interviene en 
una autoficción es el resultado de un haz de yos en movimiento, y que uno o varios de estos yos múltiples le apela y le habla." Entonces nos topamos con un autor en "un estado de esquizofrenia total" (Fuguet 124), atrapado con las voces en su propia cabeza — ellos siendo proyecciones del Cali real que lo rodea—quien utiliza la palabra escrita para encontrar solaz en sí mismo y escapar su realidad. $\mathrm{O}$ podemos considerar el reverso: la ciudad más oscura y solitaria en existencia, un mareo de espejos que atacan y edificios que aprisionan, un torbellino personal.

Entonces, ¿cómo Caicedo refleja esta fragmentación en su(s) persona(jes)? Como nos explica Carvajal (138), "la postura o actitud de los personajes caicedianos, mediante sus acciones, pensamientos y tránsito por la ciudad de Cali, revela un estado de identidad indefinida que refleja la condición histórica de un sector de la sociedad colombiana de los años sesenta". Y como nos advierte Casas, el género autoficcional no permite exclusiones. "Infección", el primero de los cuentos en Calicalabozo, un encuentro entre dos amigos hipócritas cuyo discurso se interrumpe por divagaciones sobre lo mucho que odia a Cali, lo profundo que su entorno lo hunde; un texto "autobiográfico" que Andrés escribió a los quince años, cual Fuguet también incluye en la primera sección de $M i$ cuerpo..., contiene citas que fueron reproducidas en el cuento.

En otro cuento, "El espectador", la autorreferencialidad es evidente desde el título: El Espectador es un diario en el que Caicedo trabaja más o menos a la misma edad que escribe el cuento. Su protagonista, Ricardo González-un posible avatar del mismo Ricardito el miserable en ;Que viva la música! - no sale del cine, pasa sus horas y sus días encerrados en el espacio de "la sala de cine, espacio que propicia la fantasía y se constituye en una suerte de metáfora liberadora de excepción frente a la rutina, un lugar donde lo virtual se torna real por obra y gracia de los mismos personajes" (Caicedo, Adolfo 203). Como nos explica el autor, desde sus inicios como cinéfago, se observa la soledad inherente de quien va solo a un cine y el carácter contradictorio del acercamiento de Caicedo hacia la soledad: "Fue la época en la que definitivamente comencé a ir al cine solo, qué buena fue esa época. Tendría 12, ¿13 años? Me senté 
cómodamente, muy de mañana, y vi partes de la película, y me sentí rico en mi tristeza, pretendiendo otro orden en las cosas, pretendiendo haber crecido en una dirección distinta" (Fuguet 94). Aquí también se puede observar una iniciativa en escapar su realidad, en imaginarse en otros espacios, aunque sea uno que ya haya experimentado pero que sigue transformándose con cada película que consume, así "tejiendo la ficción del hombrecito que va al cine hasta que se enloquece" (159), un especie de Quijote que se vuelve loco escuchando voces en las penumbras de una sala de cine. ${ }^{4}$

Por otro lado, "De arriba abajo de izquierda derecha" es el cuento en el que mejor podemos percibir lo que Llorca describe como "el universo cerrado de Caicedo donde dos personajes de una clase acomodada viven recluidos en su universo y se enfrentan a un conflicto exterior" (388), el mismo que sería reflejado en iQue viva la música!; es también una alusión al universo cerrado de los que conocieron a Andrés en vida, vagueando por Cali y pocos otros lugares, siempre retornando a aquella cuna materna, a aquel hervidero de perdiciones y desesperaciones, del cual nunca puede salir, aunque lo intenta: "que ni intente crear una relación con el Andrés que se encuentra en el cine club y en la universidad y por las calles de Cali y se saludan, porque esa persona no existe. Ese hombre sólo es real cuando está solo en el baño, cagando" (Fuguet 37-8). Es decir, el autor mismo interrumpe nuestra interpretación de sus textos como una voz a la oreja: ha dejado la clave para que consideremos su vida como una ficción, que aquel es sólo una proyección del Andrés que ya no está con nosotros.

Los pasados ejemplos han sido ejercicios autoficcionales más sencillos, pero en Calicalabozo, Caicedo estira y transforma su ser en maneras aún más espeluznantes. "Calibanismo" también recurre a la fusión de Cali con otra imagen

${ }^{4}$ Este cuento corresponde a gran medida a dos de las "incógnitas imperativas" que Unamuno identifica como fuerzas motoras para escribir partiendo del yo y que trata de resolver mediante su escritura (Alberca 94): el que uno cree ser, y el que los otros creen que uno es. El yo en este caso se desdobla como un personaje parecido, un espejo de uno mismo, y también en el espejo de los demás, cuando el protagonista se enfrenta con otros personajes que en vida enajenarían a un personaje solitario, cuando es visto un "especie de outsider" como Andrés fue en vida, y cómo "un cinéfilo busca en vano hablar con alguien sobre cine, línea narrativa que conserva en su interior el papel de la fascinación dentro de la configuración de su subjetividad" (Caicedo, Adolfo 204). 
tenebrosa: el caníbal, el humano que consume humanos (¿el humano/ciudad consumiendo sus habitantes?). Sin embargo, encontramos la misma angustia, el mismo trato autorreferencial; podríamos considerar éste y demás textos como lo que Gasparini considera una autofabulación (citado en Casas 28), cual presenta una "proyección del autor en situaciones imaginarias en textos en los que el pacto de lectura es inequívocamente novelesco". Es una oportunidad del autor para sentarse en el confesionario de un reality show y escupir a la cámara las perversidades más atroces que en vida jamás pudo comunicar (y, suponemos, realizar), privilegiándose de la autoficción, lo que Alberca señala como "una máscara invisible o un escondite transparente, pues tras esa identidad ficticia que simula ser real, el autor puede hablar de sí mismo sin ser evaluado o molestado" (92). Otro cuento, "Besacalles", logra otra autofabulación, pero añadiendo otro nivel diegético que no revela hasta el final:

El travestismo discursivo es un rasgo notable también en el cuento "Besacalles" que Caicedo escribió a los 17 años, cuya narradora se revela en los últimos renglones como una prostituta travesti. Esa revelación final obliga a releer el cuento, donde de repente muchos detalles desapercibidos por el género gramatical femenino que usa siempre la narradora: el rechazo por parte de su familia a su afición de salir en busca de muchachos, o su miedo de encontrarse con ciertos muchachos, cobran un nuevo sentido con la referencialidad a golpe que ese muchacho le da en los testículos. Las referencias despectivas como maricas y maricones, y la amenaza constante de una violencia homofóbica son frecuente en muchos cuentos de Caicedo... (Balderston 25)

Esto no solamente rompe con concepciones de sexualidad en un tiempo en que rechazar concepciones tradicionalistas resulta una tarea onerosa, sino que también representa la época en la que le toca vivir: "se generaliza la moda 
unisexo, que intenta borrar la distinción entre los sexos; los temas sexuales, lo reprimido y lo inconsciente comienzan a ser asuntos ampliamente debatidos..." (Gómez 216). El conflicto con la homofobia podría ser reflejo de aquella relación ambigua con el sexo que tanto reverbera en Mi cuerpo..., cual varía desde una asexualidad autodiagnosticada- - "Definitivamente que no tengo ningún interés en esa serie de combinaciones que llaman 'lo sexual"' (Fuguet 131) — a una rebeldía sin causa_-"Pensé regresar... con una mujer vestida de hombre que no hablara sino de literatura. Ésa era mi fantasía" (Fuguet 90) — hasta una confesión inusitada - "Yo también tuve un periodo homosexual, Hernando, tuve un romance con Guillermito Lemos; cuando ya me parecía que empezaba a detestar definitivamente a las mujeres, pero llegó Patricia y se acabó todo. Además, en mi casa me prohibieron la junta con los Lemos, pues los acusan de ser los culpables de mi drogomanía" (216). Si añadimos el plano de las drogas-la desconexión que crea con el mundo que lo rodea, la soledad que usuarios adictos experimentan-entendemos por qué Andrés dice que desempeña "una mejor función si el objeto es escogido en órdenes anormales (prostitución, masculino, poca estabilidad emocional), en cambio hay un temor creciente cuando se trata, por ejemplo, de una muchacha distinguida por su corrección e inteligencia" (Fuguet 168); esto se plasma claramente en el cuento. La sexualidad humana, por naturaleza, es ambigua y contradictoria; no debería sorprendernos, entonces, imaginarnos a Caicedo como aquel/la protagonista que vaguea por Cali con y sin ganas de encontrarse con nadie, esquivando rostros conocidos y personas que pudieran hacerle daño, acorde con el Caicedo que, en vida, comenta: "No resisto esta soledad, busco compañía y no resisto la compañía... Casi me despellejo vivo buscando un objeto de amor, alguna criatura con gracia que me inspirara a mejores pensamientos" (131).

Leer un texto o ir al cine no son las únicas maneras en que el ser humano puede escapar su realidad inmediata: también se puede considerar la experiencia de escribir -y más aún, escribir sobre uno mismo y así escapar la cotidianidad, inscribirse en otra existencia parecida o paralela, quizá otra persona enteramente, 
e imaginarse en otros lares sin importar lo depravado o lo insólito. En Caicedo encontramos que nutrirse de su propia historia fue más que una fuerza motriz: termina siendo un exorcismo violento y prolongado, la catástrofe de un accidente de tren proyectado en cámara lenta, y el foco del grosor de su producción literaria. Sirve como motivo para reexplorar sus angustias y reescribir aspectos de su vida que cambiaría, que hubiera querido finalizar de manera distinta, o simplemente para proveerle permanencia a un espacio y un tiempo que, para él, resultó infinitamente insuperable. A través de su palabra escrita es que sus lectores/as descubren quién verdaderamente fue, allá quemándose vivo en el hervidero ardiente de Cali, tan así que su persona es inseparable de sus personajes. Y con cada año añadido a su corta (pero explosiva) carrera pública de escritor, más reverbera aquella descentralización en sus escritos de maneras impresionantes, contradictorias y, en muchas instancias, ambiguas. Ha creado una ciudad entera para él mismo existir, con proyecciones de él mismo, con sus espejos, y todos aquellos demonios que lo atormentaron en vida también cobrando eternidad, también sobreviviendo aquella angustia de vivir enjaulado - como siempre ha existido, como siempre existirá. Pero Caicedo estira la mano desde ese fuego que lo consume no para que lo salven, sino para que nadie en el futuro tuviera que quemar como él. 


\section{Bibliografía}

Alberca, Manuel. “¡Éste (no) soy yo?” Pasajes 25 (2007-8): 88-101. Web.

Balderston, Daniel. "Baladas de la loca alegría: literatura queer en Colombia." Otros cuerpos, otras sexualidades. Bogotá: Universidad Javeriana, 2008. 16-33. Web.

Barthes, Roland. "La muerte del autor." Trad. C. Fernández Medrano. La Letra del Escriba 15. 2006. Web.

Caicedo, Adolfo. "Imaginarios urbanos en Calicalabozo de Andrés Caicedo." La Estela de Caicedo. Miradas, críticas. Ed. Juan Duchesne Winter \& Felipe Gómez Gutiérrez. Pittsburgh: Instituto Internacional de Literatura Iberoamericana, 2009. 185-208. Impreso.

Caicedo Estela, Andrés. Calicalabozo. Bogotá: Grupo Editorial Norma, 2008. Impreso.

—_ ¡Que viva la música! Bogotá: Plaza \& Janes, 1990. Impreso.

Caicedo Estela, Rosario. "A mi hermano le gustaba ir al cine." La Stela de Caicedo. Miradas críticas. Ed. Juan Duchesne Winter y Felipe Gómez Gutiérrez. Pittsburgh: Instituto Internacional de Literatura Iberoamericana, 2009. 21-26. Impreso.

Carvajal Córdoba, Ernesto. "El sujeto cultural o la representación indefinida de la sociedad colombiana de los años sesenta en las obras de Andrés Caicedo.” La Estela de Caicedo. Miradas críticas. Ed. Juan Duchesne Winter \& Felipe Gómez Gutiérrez. Pittsburgh: Instituto Internacional de Literatura Iberoamericana, 2009. 137-166. Impreso.

Casas, Ana, ed. La autoficción. Reflexiones teóricas. Madrid: Arco/Libros, S.L., 2012. Impreso. 
Fuguet, Alberto. Mi cuerpo es una celda: una autobiografía. Bogotpo es una celda: una autobiografíao.h: I

Gómez Serrudo, Nelson Antonio. “Andrés Caicedo en clave urbana." La Estela de Caicedo. Miradas críticas. Ed. Juan Duchesne Winter \& Felipe Gómez Gutiérrez. Pittsburgh: Instituto Internacional de Literatura Iberoamericana, 2009. 209-225. Impreso.

Llorca, Joaquín. "Cine, ciudad y arquitectura, apuntes metodológicos. El caso de El grupo de Cali." CS 9 (2012): 369-390. Web. 